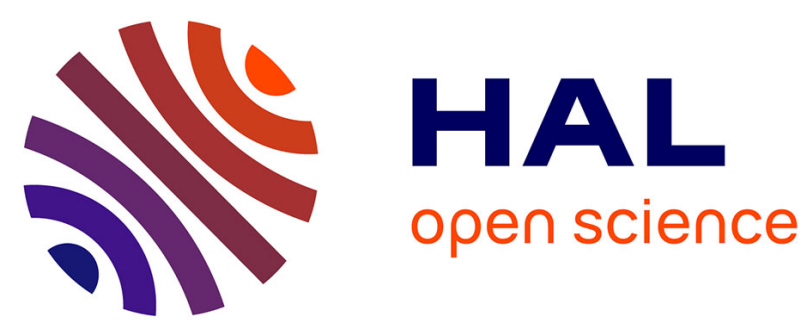

\title{
Femtosecond laser micromachining of crystalline silicon for ablation of deep macro-sized cavities for silicon-on-insulator applications
}

Arun Bhaskar, Justine Philippe, Flavie Braud, Etienne Okada, J.F. Robillard, Daniel Gloria, Christophe Gaquière, Emmanuel Dubois

\section{To cite this version:}

Arun Bhaskar, Justine Philippe, Flavie Braud, Etienne Okada, J.F. Robillard, et al.. Femtosecond laser micromachining of crystalline silicon for ablation of deep macro-sized cavities for silicon-oninsulator applications. SPIE Photonics West, Conference 10906 - Laser-based Micro- and Nanoprocessing XIII, Feb 2019, San Francisco, United States. 109060K, 13 p., 10.1117/12.2507652 . hal02317233

\section{HAL Id: hal-02317233 \\ https://hal.science/hal-02317233}

Submitted on 24 Aug 2021

HAL is a multi-disciplinary open access archive for the deposit and dissemination of scientific research documents, whether they are published or not. The documents may come from teaching and research institutions in France or abroad, or from public or private research centers.
L'archive ouverte pluridisciplinaire HAL, est destinée au dépôt et à la diffusion de documents scientifiques de niveau recherche, publiés ou non, émanant des établissements d'enseignement et de recherche français ou étrangers, des laboratoires publics ou privés. 


\title{
Femtosecond laser micromachining of crystalline silicon for ablation of deep macro-sized cavities for Silicon-on-Insulator applications
}

\author{
Arun Bhaskar*1,2, Justine Philippe ${ }^{1}$, Flavie Braud ${ }^{1}$, Etienne Okada ${ }^{1}$, Jean-François Robillard ${ }^{1}$, \\ Daniel Gloria $^{2}$, Christophe Gaquière ${ }^{1}$, Emmanuel Dubois ${ }^{1}$ \\ ${ }^{1}$ Univ. Lille, CNRS, Centrale Lille, ISEN, Univ. Valenciennes, UMR 8520 - IEMN, F-59000 Lille, \\ France \\ ${ }^{2}$ STMicroelectronics, 850 Rue Jean Monnet, FR-38926 Crolles
}

\begin{abstract}
We demonstrate the use of femtosecond laser micromachining for ablating macro-sized cavities in crystalline silicon. The method employed is laser milling in which the focused laser beam is raster scanned over the area to be removed. We report the achievement of very high volume ablation rates for the cavity of up to $8.48 \times 10^{6} \mu \mathrm{m}^{3} \mathrm{~s}^{-1}$. To achieve such high rates, we make use of a high average power fiber laser source of $1030 \mathrm{~nm}$ wavelength and variable per pulse energy of up to $100 \mu \mathrm{J}$. By carefully controlling the process variables such as pulse energy, repetition rate and scanner speed, the tradeoffs between micromachining quality and ablation rate are quantified. The developed process is applied on Siliconon-Insulator (SOI) wafers for improving performance of RF devices. By making use of laser removal and an additional step of selective silicon etch using $\mathrm{XeF}_{2}$, handler silicon is removed completely under RF circuits such as SP9T switch. The local removal of silicon under such circuits completely eliminates the losses and non-linearities caused by the coupling of RF signals to the semi-conducting substrate. Small-signal and large-signal RF measurements are performed before and after substrate removal to quantify the performance gain. The obtained performance after substrate removal is better than specialized RF-SOI substrates such as trap-rich SOI. This is of practical significance for next generation wireless technologies like $5 \mathrm{G}$ which operate at higher frequencies with stringent specifications. The proposed method is also potentially useful for fabricating membrane based devices in SOI technology such as pressure sensors.
\end{abstract}

Keywords: Laser Micromachining, High speed ablation, Laser Milling, Large area ablation, Silicon-on-Insulator (SOI) technology, SOI RF membranes

\section{INTRODUCTION}

Femtosecond laser micromachining is an emerging tool for controlled modification and ablation of different types of materials like metals, semiconductors, dielectrics, ceramics etc. The processing throughput of femtosecond lasers depends on two important factors which are laser power and laser beam guiding apparatus. The latest generation of femtosecond lasers are capable of delivering an average power output in excess of $1 \mathrm{~kW}^{1}$. While such high power is not possible in older generation of lasers like the one used in this work, it will be demonstrated that significantly high removal rates can be achieved nonetheless. For high power laser source, the laser power is typically delivered at a high repetition rate of the order of several MHz. In order to have an optimal spatial overlap between successive laser pulses, a high speed beam guiding apparatus is essential, which is typically galvanometric xy scanner system (galvo). For high throughput micromachining, the galvo scan speed requirement is several $\mathrm{ms}^{-1}$ and recently galvo systems have evolved which are capable of galvo speeds of over $10 \mathrm{~ms}^{-12}$. This capability makes it possible to use the maximum power for micromachining while minimizing heat accumulation effect ${ }^{3}$, which can significantly increase the heat affected zone. This makes femtosecond laser micromachining a powerful tool for high quality and throughput micromachining.

Femtosecond laser processing of silicon has attracted significant attention in the recent past with possible applications like laser dicing ${ }^{4}$, photovoltaics ${ }^{5}$, photonics ${ }^{6}$, MEMS ${ }^{7}$ etc. Most of the reported applications involve scribing of lines in silicon. There have been a few studies which have reported large area ablation of silicon ${ }^{8-10}$. However, this has not been explored largely for practical applications.

*arun.bhaskar@isen.iemn.univ-lille1.fr $\quad$; phone: $\quad 3303201979$ 17; $\quad$ www.iemn.fr 
Silicon on insulator (SOI) technology is a large scale technology which is used in the semiconductor industry. SOI wafers consist of a thin layer of silicon which contains the active devices. This thin layer is supported by a thick layer of silicon called handler silicon. There is an insulating layer in between the two silicon layers called the buried oxide (BOX). This layer acts as electrical insulation for the active devices in the thin silicon layer. This improves performance significantly with respect to bulk silicon technology ${ }^{11}$.

While handler silicon acts as the support layer for the active silicon, its presence degrades electronic performance because of non-linear coupling and losses in the substrate ${ }^{12}$. Since, handler silicon is physically not required for the electronic functionality of circuits, it is interesting to explore the benefits of removing handler silicon locally under RF circuits. The backside etching of silicon has been previously reported for different applications using techniques such as DRIE ${ }^{13}$, TMAH etch ${ }^{14}$ etc. These methods have several drawbacks like slow etching rate, poor control of etching geometry etc.

Laser micromachining is potentially a good method for local etching of silicon, given its high throughput and high quality capabilities. In this study, large area micromachining is studied which uses the method of laser milling. The laser micromachining is followed by a step of $\mathrm{XeF}_{2}$ etching to create SOI membranes on pre-fabricated circuits. While our interest is primarily RF circuits, the developed process can be used for multiple applications like microheaters, gas and flow sensors, pressure sensors ${ }^{15}$ etc. The developed process is referred to as Femtosecond Laser Assisted Micromachining and Etching (FLAME) process. The different aspects related to the FLAME process is discussed in section 2. SOI membranes are created for SP9T circuit and RF characterization is performed to determine the impact of handler substrate on RF performance, which is discussed in section 3.

\section{FLAME PROCESS}

\subsection{Description of laser system}

The laser system that is presented in this work comprises of the fiber laser head Tangerine (Amplitude Systèmes). The fundamental output of the laser head is centered at a wavelength of $1030 \mathrm{~nm}$. The second and third harmonic generator modules enables frequency up-conversion of the fundamental and provides the possibility of using two additional wavelengths of $515 \mathrm{~nm}$ and $343 \mathrm{~nm}$. The maximum power at the workpiece is $13 \mathrm{~W}, 3.8 \mathrm{~W}$ and $1 \mathrm{~W}$ for source wavelengths of $1030 \mathrm{~nm}, 515 \mathrm{~nm}$ and $343 \mathrm{~nm}$ respectively. The power delivered by each source can additionally be controlled by means of optical attenuators. In this paper, we primarily focus on laser processing using $343 \mathrm{~nm}$ and 1030 $\mathrm{nm}$ source. The $515 \mathrm{~nm}$ source is not studied because of the poor speed capability of the galvanometric scanner installed in this line. The spot size of the focused laser beam is $5 \mu \mathrm{m}$ and $15 \mu \mathrm{m}$ for sources $343 \mathrm{~nm}$ and $1030 \mathrm{~nm}$ respectively. The laser pulse width is $350 \mathrm{fs}$.

There are 3 optical/mechanical components of the laser system which enable the displacement of the workpiece with respect to the laser spot: linear positioning stage, trepanning head and galvanometric scanner. The displacement field of the galvanometric scanner is $50 \times 50 \mathrm{~mm}^{2}$ and is the most suitable for our application. The trepanning head consists of multiple wedges which can rotate with respect to each other and produce spiral trajectories of the beam. This is suitable for processing circular areas. The linear stage is not used in this work as it does not permit movement of workpiece at high speed because of mechanical instability during stage displacement.

\subsection{Study of trenches scribed in silicon}

The study of trenches scribed in silicon is useful to determine the optimal conditions for performing laser milling. In our previous study, we had described the scribing of trenches for the $1030 \mathrm{~nm}$ source ${ }^{16}$. In this publication, the scribing of trenches is discussed for both the $343 \mathrm{~nm}$ and $1030 \mathrm{~nm}$ source. In particular, the profiles of trenches are studied along their length. These profiles reveal information which is important while developing the final milling process.

Initially, the effect of galvo speed is studied at low power for $343 \mathrm{~nm}$ source. Fig. 1 depicts the profile of trenches obtained using optical profilometry (Bruker) for $343 \mathrm{~nm}$ source at varying galvo speeds and a pulse repetition frequency of $200 \mathrm{kHz}$. This is the frequency at which the output power of the laser is the maximum for all 3 sources. It can be seen that for lower speeds, the trenches are deeper, but there is more melting of silicon because of heat accumulation effect ${ }^{3}$. For galvo speed of $25 \mathrm{~mm} \mathrm{~s}^{-1}$, this effect is clearly visible where there are plenty of red spots which correspond to the regions where silicon is resolidified from molten phase. The fused material accumulates inside and along the edges of 
the trench. At higher speeds, the occurrence of red spots is greatly reduced. At $100 \mathrm{~mm} \mathrm{~s}^{-1}$, the red spots are almost nonexistent suggesting that thermal effects are minimal at this speed.

(a)

(b)

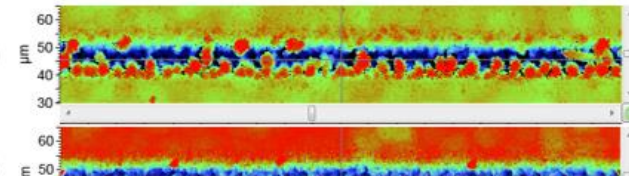

(c)

(d)

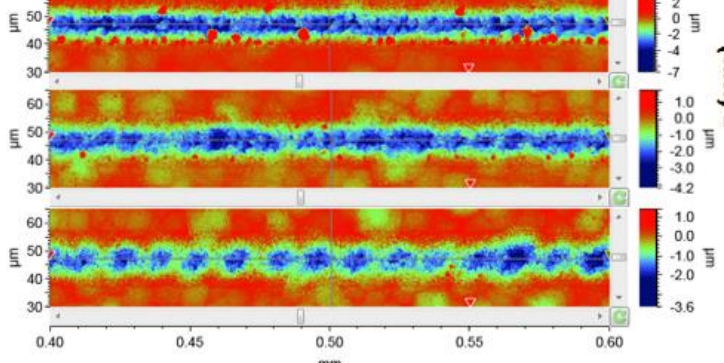

Molten Si

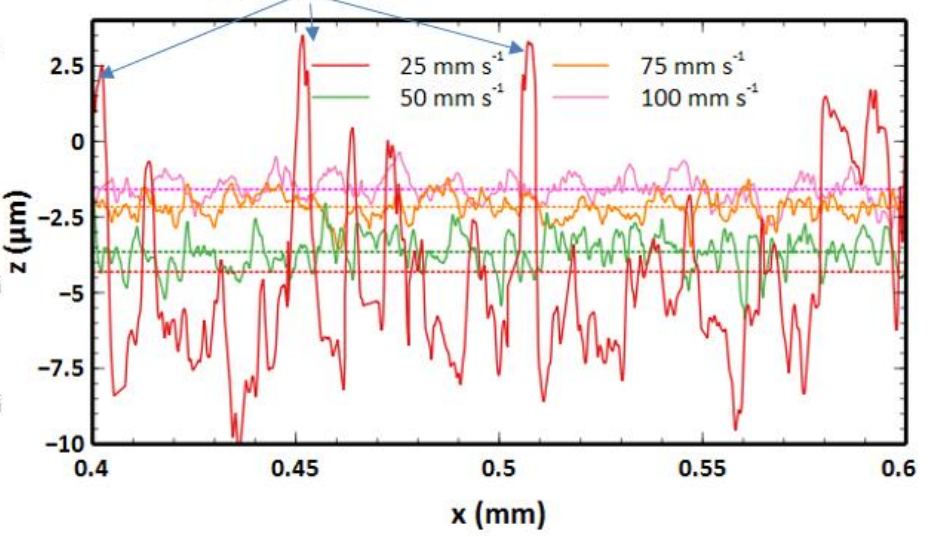

Figure 1. Profilometer scans of lines scribed in silicon using $343 \mathrm{~nm}$ source at laser power of $0.44 \mathrm{~W}$ and galvo speed of (a) $25 \mathrm{~mm} \mathrm{~s}^{-1}$ (b) $50 \mathrm{~mm} \mathrm{~s}^{-1}$ (c) $75 \mathrm{~mm} \mathrm{~s}^{-1}$ (d) $100 \mathrm{~mm} \mathrm{~s}^{-1}$. The trench profile taken at its and along its length shown in the graph

Having seen that higher scribing speeds result in lesser melting of material, the scribing of lines is studied at higher power at a galvo speed of $100 \mathrm{~mm} \mathrm{~s}^{-1}$. As seen in Fig. 2, the depth of the trench increases with increasing laser power. However, there is appearance of locally deep structures in the form of microholes which are far deeper than the average depth of the trench. At laser power of $0.93 \mathrm{~W}$, the local depth of the trench exceeds the profilometer measurement limit for microholes which is $\sim 11-13 \mu \mathrm{m}$. It can also be seen that, with increasing laser power, melting and resolidification occurs along the sides of the trenches. The red lines along the sides of trench are the regions where the melt is resolidified. Thus, both the galvo speed and laser power together influence the thermal effects during laser processing.

The $343 \mathrm{~nm}$ source is found to be suitable for scribing lines with a low removal rate and narrow width of cut. Higher removal rates by making use of higher laser power result in hole like morphologies which is not desirable when applied to a larger area during milling. There are other process parameters that could optimize the scribing quality further such as out of focus milling and pulse overlap optimization. However, because of the limited power output capability of the $343 \mathrm{~nm}$ source, further optimization would not yield considerably higher ablation rates and thus it is interesting to explore the high power output of $1030 \mathrm{~nm}$ source for micromachining.

(a)

(b)

(c)

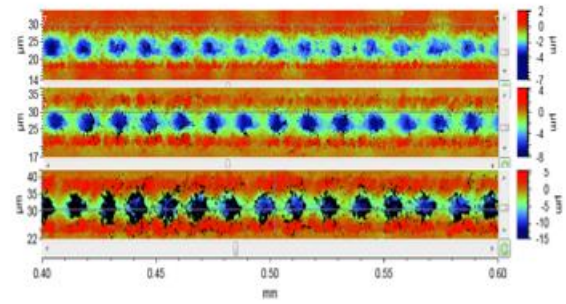

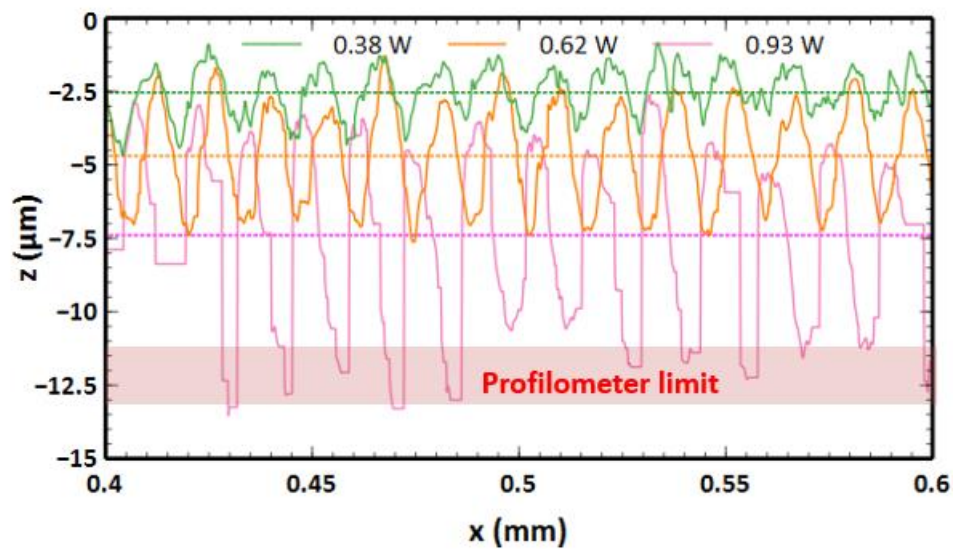

Figure 2. Profilometer scans of lines scribed in silicon using $343 \mathrm{~nm}$ source at galvo speed of $100 \mathrm{~mm} \mathrm{~s}^{-1}$ and laser power of (a) $0.38 \mathrm{~W}$ (b) $0.62 \mathrm{~W}$ (c) $0.93 \mathrm{~W}$. The trench profile taken at its centre and along its length shown in the graph

For the $1030 \mathrm{~nm}$ source, the peak output power is too high for scribing at the peak output frequency of $200 \mathrm{kHz}$. When the frequency is kept constant and the pulse energy is attenuated using the optical attenuator to have an output power $\sim 1$ $\mathrm{W}$, similar scribing features (narrow holes) are found for both sources.However, this problem can be overcome for the 
$1030 \mathrm{~nm}$ source by reducing the pulse repetition rate and keeping the pulse energy unaltered. Fig. 3 shows the profile of lines scribed using $1030 \mathrm{~nm}$ source at varying galvo speeds at low power. It can be seen that, there is no significant redeposition of melt in the region of ablation. The resolidification occurs along the sides of the trench. It can also be seen that the depth of scribing is smaller for $1030 \mathrm{~nm}$ source as compared to $343 \mathrm{~nm}$ source. This difference can be explained by the fact that the spot size is bigger for $1030 \mathrm{~nm}$ source and correspondingly depth of ablation is reduced due to reduced peak fluence.

(a)

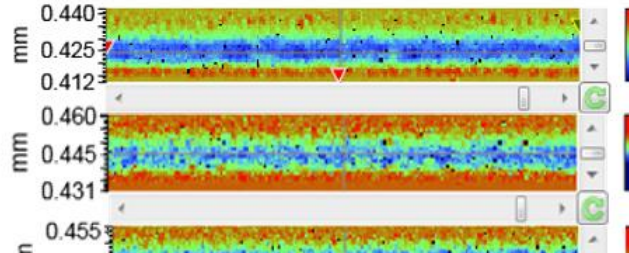

(c)
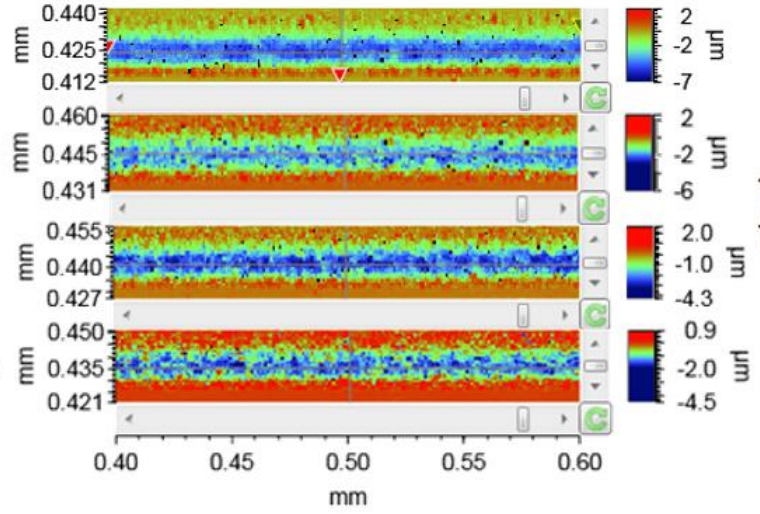

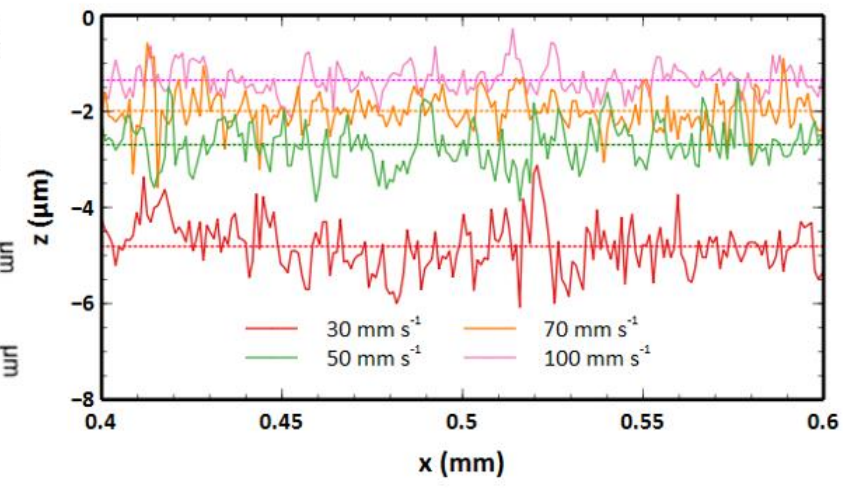

Figure 3. Profilometer scans of lines scribed in silicon using $1030 \mathrm{~nm}$ source at laser power of $0.43 \mathrm{~W}$ and galvo speed of (a) $30 \mathrm{~mm} \mathrm{~s}^{-1}$ (b) $50 \mathrm{~mm} \mathrm{~s}^{-1}$ (c) $70 \mathrm{~mm} \mathrm{~s}^{-1}$ (d) $100 \mathrm{~mm} \mathrm{~s}^{-1}$. The trench profile taken at its centre shown in the graph

As in the case of $343 \mathrm{~nm}$ source, higher galvo speeds result in lesser melting of material for $1030 \mathrm{~nm}$ source. While galvo speeds are reported upto $100 \mathrm{~mm} \mathrm{~s}^{-1}$ in Fig. 3 , the speeds that can be used for micromachining are only upto 30 $\mathrm{mm} \mathrm{s}^{-1}$. This is because galvo movement is unstable at sharp turns at higher speeds ${ }^{16}$. For the $1030 \mathrm{~nm}$ source, the effect of laser power on ablation is studied at $30 \mathrm{~mm} \mathrm{~s}^{-1}$ and the obtained profiles are shown in Fig. 4 For the highest power of $1.46 \mathrm{~W}$, the average depth is $\sim 13 \mu \mathrm{m}$ and there are no narrow hole like morphologies that are seen at the bottom of the trench. Thus, $1030 \mathrm{~nm}$ source is found to be adaptable for micromachining at both high and low removal rate. Fig. 4d depicts the profile of the trench which will be used for step 1 of milling of SP9T switch, which is discussed later.

(a)

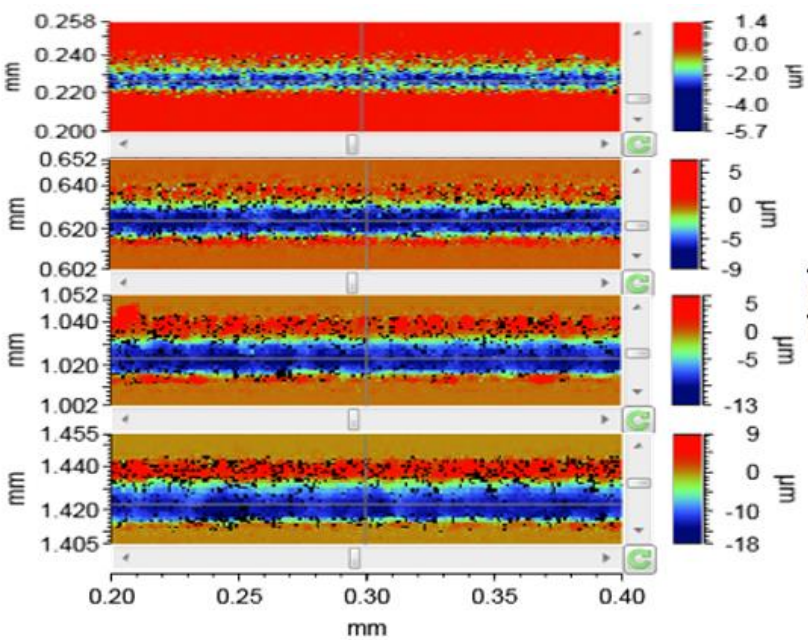

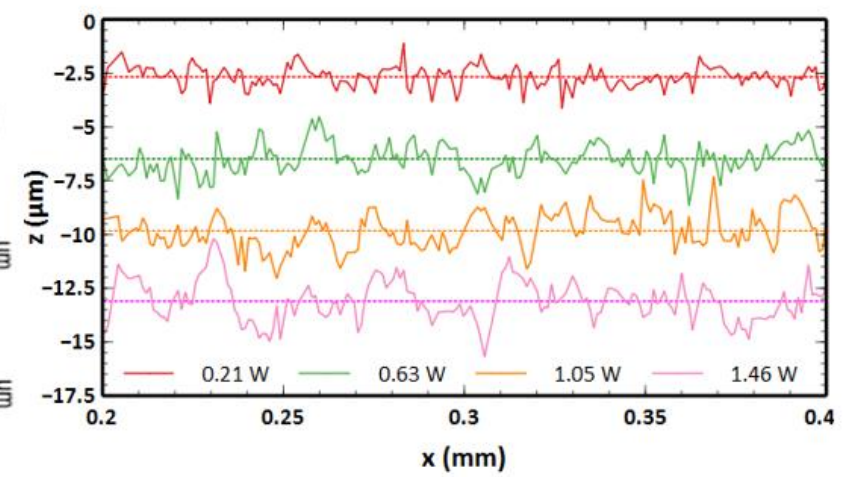

Figure 4. Profilometer scans of lines scribed in silicon using $1030 \mathrm{~nm}$ source at galvo speed of $30 \mathrm{~mm} \mathrm{~s}^{-1}$ and laser power of (a) $0.21 \mathrm{~W}$ (b) $0.63 \mathrm{~W}$ (c) $1.05 \mathrm{~W}$ (d) $1.46 \mathrm{~W}$. The trench profile taken at its centre and along its length shown in the graph

Having seen that $1030 \mathrm{~nm}$ source is suitable for micromachining of silicon, it is useful to have the depth information for the trench over a wide range of processing parameters. Fig. 5 depicts the depth of the trench for different galvo speeds and laser power. At lower galvo speeds, the difference in depth is larger for varying laser power and the difference reduces for higher galvo speeds. At a given power, the depth is inversely proportional to the galvo speed which is 
consistent with results obtained by Crawford et. al ${ }^{17}$. This is because of the fact that accumulated laser fluence depends inversely on the galvo speed. At constant speed, the depth varies linearly as a function of power. Hence, it is easier to choose a constant speed of milling in order to fine tune the process.

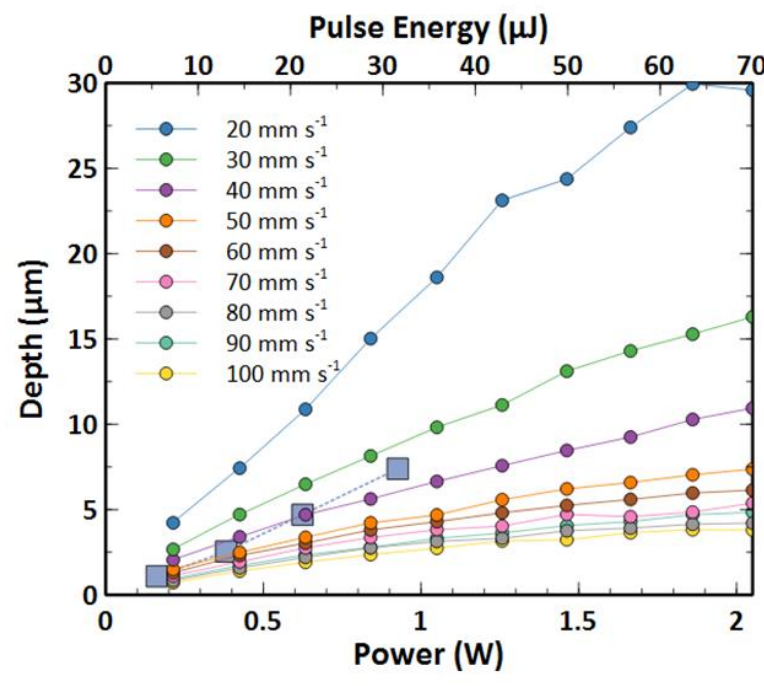

(a)

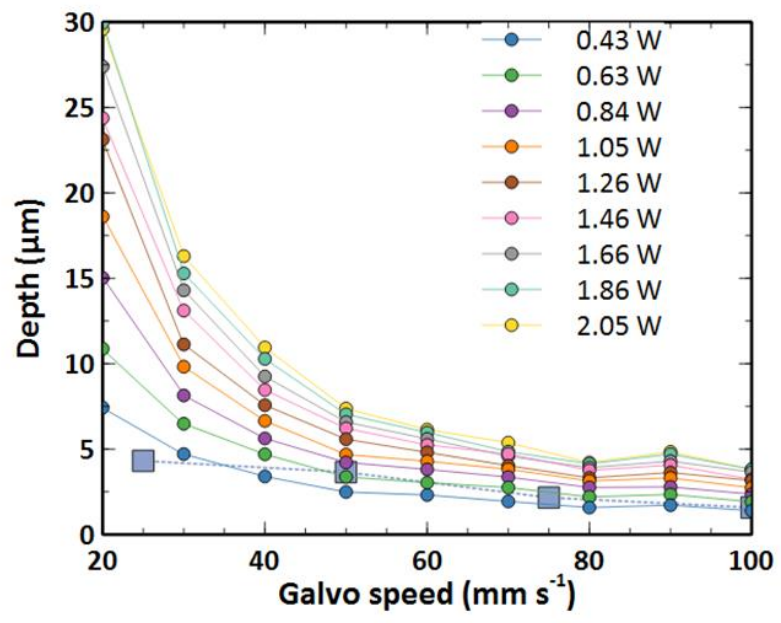

(b)

Figure 5. Depth of trenches measured at the trench centre at different laser powers and galvo speeds for $1030 \mathrm{~nm}$ source.

The blue squares represent the depths obtained for $343 \mathrm{~nm}$ source (a) Scanning speed: $100 \mathrm{~mm} \mathrm{~s}^{-1}$ (b) Power: $0.443 \mathrm{~W}$.

With increasing laser power, the melting of material is more severe and results in a larger heat affected zone and consequently more sub-surface damage. It is difficult to directly measure the heat affected zone. However, we have come up with the method of $\mathrm{R}_{\mathrm{z}}$ analysis to quantify the thermal impact of a certain set of process parameters. While this method is not intended to know directly the heat affected zone, it allows to have a comparison of thermal impact when the process parameters are changed. $R_{z}$ refers to the average of the 10 highest points taken in a profilometer scan. These 10 points correspond to the region of melt along the sides of the trench and thus represent the peak height of molten silicon averaged over 10 points.

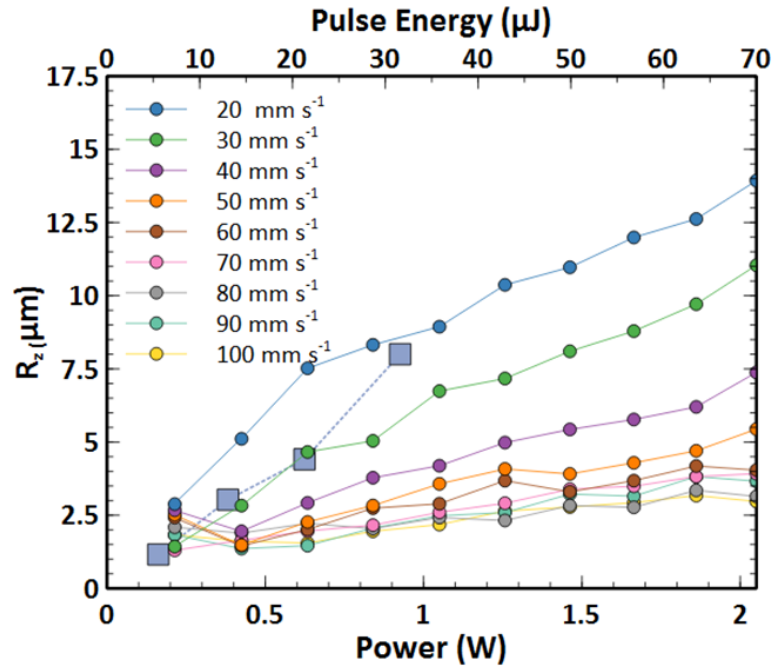

(a)

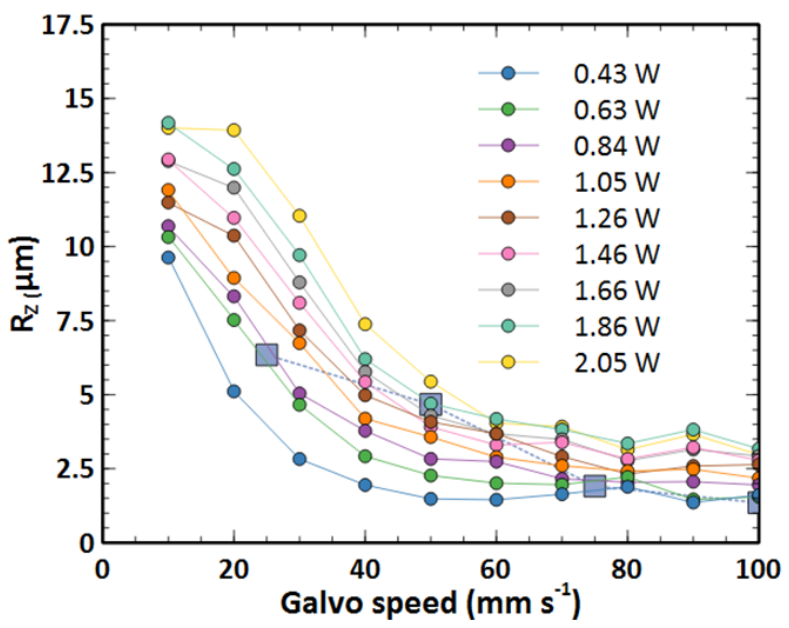

(b)

Figure 6. Rz value obtained from melt along the sides of the trench at different laser powers and galvo speeds for $1030 \mathrm{~nm}$ source. The blue squares represent the $\mathrm{R}_{\mathrm{z}}$ for $343 \mathrm{~nm}$ source (a) Scanning speed: $100 \mathrm{~mm} \mathrm{~s}^{-1}$ (b) Power: $0.443 \mathrm{~W}$. 
The Rz values are plotted for different set of processing parameters in Fig. 6. It can be seen that the overall trend for Rz as a function of galvo speed and power is the same as for depth. Larger depth of scribed line results in more melting of silicon and thus when higher ablation rates are preferred, it comes at the cost of larger heat affected zone and sub-surface melting. It is also interesting to compare the thermal impact between the $343 \mathrm{~nm}$ source and the $1030 \mathrm{~nm}$ source. On a preliminary comparison between the green curve $(1030 \mathrm{~nm})$ and the 343 curve in Fig. 5 and Fig. 6, for the same depth of etch, the Rz values are similar for both sources. It appears that the thermal effect scales with the depth of etch. However, further examination is necessary by comparing a larger dataset to have a better comparison.

\subsection{Description of FLAME process}

The FLAME process to create membranes in SOI dies is described in Fig. 7. The backside of the SOI die (thickness: $\sim 750 \mu \mathrm{m}$ ) is laminated with a $10 \mu \mathrm{m}$ Ajinomoto GX-T31 film. After this step, laser micromachining is performed using the technique of laser milling in the area where membrane needs to be formed. Depending on the laser processing parameters used, the ablation is stopped when the remaining thickness of the handler substrate under the membrane to be suspended is $50-100 \mu \mathrm{m}$. This remaining part of the handler substrate is removed by using $\mathrm{XeF}_{2}$ etching which has a high selectivity of etching over $\mathrm{SiO}_{2}$ (1000:1). Ajinomoto film acts as the etch-protect layer for the rest of the die where ablation is not performed. Since $\mathrm{XeF}_{2}$ etching is isotropic, the final area of the membrane is slightly larger than the area where ablation is performed.

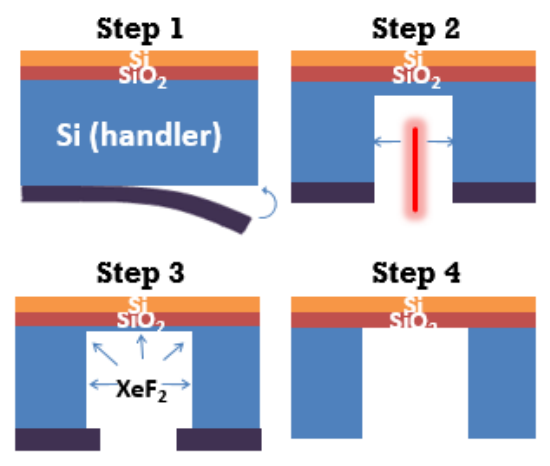

(a)

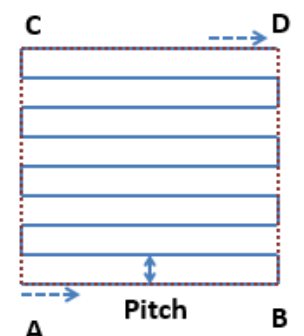

(b)

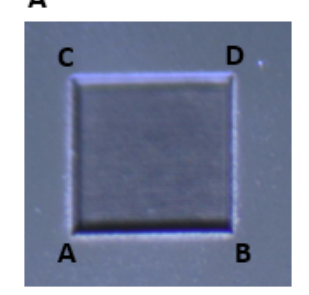

Figure 7. FLAME process steps: (1) Etch protect layer (Ajinomoto) lamination (2) Laser milling under the circuit (3) $\mathrm{XeF}_{2}$ dry etching until BOX (4) Removal of Etch protect layer in Acetone. Illustration of laser milling depicting (a) Beam trajectory (b) Cavity obtained from laser milling

\subsection{Laser milling}

Laser milling is the most important step of the FLAME process. In our experiments, a constant pitch of $10 \mu \mathrm{m}$ is used for all cavities. This pitch was chosen because it was found to be suitable both for high power and low power milling recipes. Laser milling has been explained in detail in previous work ${ }^{16}$. Some additional points are introduced here.

When laser milling is performed, an additional factor needs to be considered. Redeposition of material occurs from the laser plume that is ejected in the region of ablation The quantity of redeposition from the plume depends on the diffusion of ejected matter away from the ablated area. Hence, aspect ratio of the milling geometry plays an important role in the redeposition process. This is illustrated in Fig. 8. In both cases, four smaller square cavities of side $250 \mu \mathrm{m}$ are made within a larger square cavity. The depth of the larger cavity is $450 \mu \mathrm{m}$. In the two cases, the $\mathrm{x}-\mathrm{y}$ dimension of the larger cavity is varied. In case 1, the larger cavity has a side of $1.55 \mathrm{~mm}$ and the diffusion of ejected matter is restricted as compared to case 2 which has the larger cavity side equal to $2.5 \mathrm{~mm}$. It can be seen that there is redeposition of ejected matter in both cases. In case 1 , the redeposition is so prominent that the 4 smaller cavities are completely covered in redeposited material. In case 2, the redeposition is relatively smaller around the edges of the smaller cavity. After blowing the larger cavity with a handheld $\mathrm{N}_{2}$ air blower, it can be seen that much of the redeposited material can be removed in both the cases which is loosely bound to the cavity. The average depth of the four smaller cavities after air blow is $575 \mu \mathrm{m}$ and $600 \mu \mathrm{m}$ respectively. Thus, ablation still takes place even in the presence of redeposited material but 
removal rate is reduced and the milling geometry can be distorted. The redeposited material in the region of ablation makes it difficult to process geometries with high aspect ratio. It is also unclear what quantity of the ejected matter redeposits firmly on the surface forming redeposition layers.

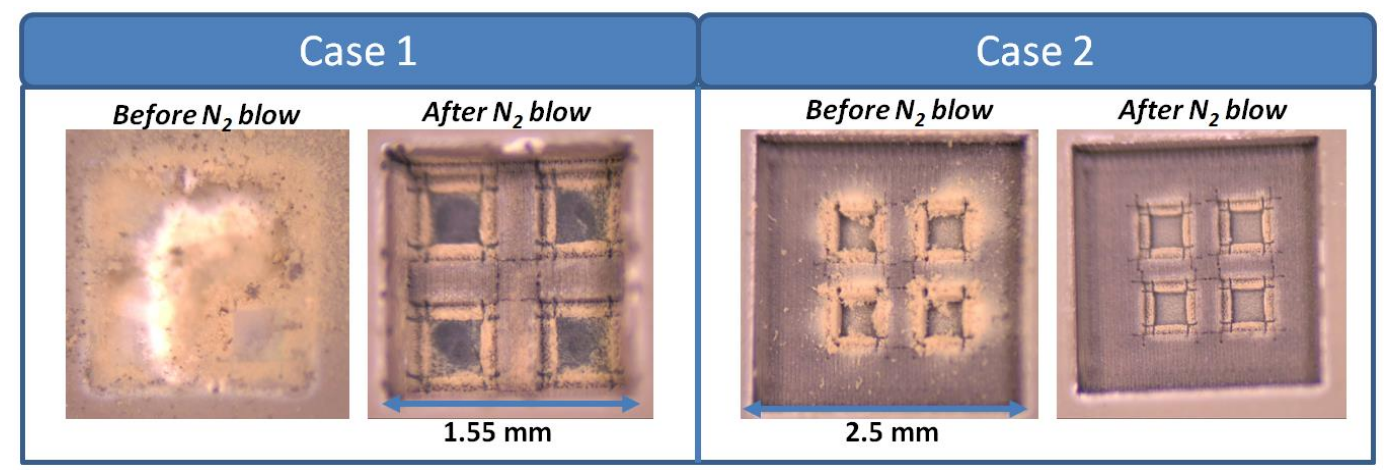

Figure 8. Study of redeposition during milling: (Case 1) Diffusion of laser plume from narrow opening (Case 2) Diffusion of laser plume from wide opening. Large cavity milling parameters: Galvo Speed $-50 \mathrm{~mm} \mathrm{~s}^{-1}$, Power-1.95 W, No. of scans - 12. Small cavity milling parameters: Galvo speed $-10 \mathrm{~mm} \mathrm{~s}^{-1}$, Power $-0.03 \mathrm{~W}$, No. of scans - 80

As a result of a combination of ablation, resolidification and redeposition processes going on during laser micromachining, the quality of the obtained cavity can vary a lot depending on chosen laser processing parameters. Fig. 9 compares two set of parameters used for laser milling. It can be seen that the bottom of the cavity is not even and locally the depth can vary at different locations. In case 1, the bottom half of the cavity has a larger depth as compared to the top half. The reverse is true for case 2 where the bottom half of the cavity has a lesser depth as compared to top half. However, the global variation in depth can be known by plotting the distribution of depths as shown in Fig 9c. The depth window is defined, which is a measure of spread of depths within the cavity. The depth window is defined as 6 times the value of the standard deviation of the Gaussian fit on the depth distribution which contains $99.7 \%$ of the points in the bottom of the cavity. It approximately measures the distance between the lowest and highest point within the cavity. A larger window represents a larger variation of depth within the cavity. The average depth of the cavity is $98.2 \mu \mathrm{m}$ for case 1 and $109.6 \mu \mathrm{m}$ for case 2. For approximately the same depth of cavity, the depth window for case 1 is $22.1 \mu \mathrm{m}$ and is smaller than for case 2 which is 37.7 .

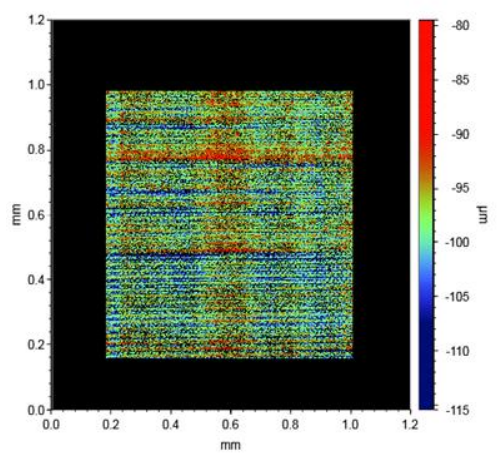

(a)

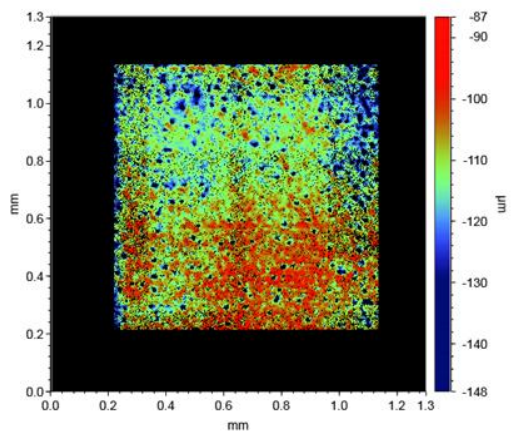

(b)

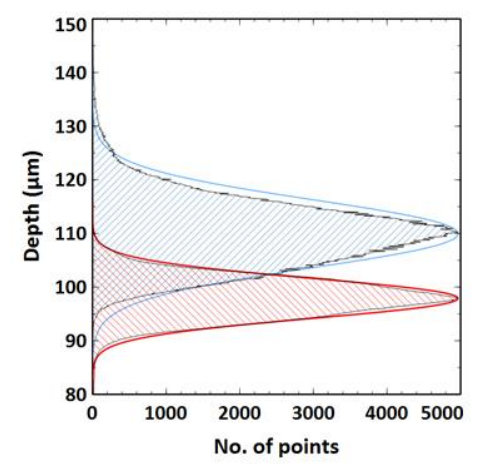

(c)

Figure 9. Profilometer scan of $1 \mathrm{~mm}$ x $1 \mathrm{~mm}$ milled using (a) $343 \mathrm{~nm}$ source, Galvo speed $-100 \mathrm{~mm} \mathrm{~s}^{-1}$, Power - $1 \mathrm{~W}$, No. of scans - 40 (b) $1030 \mathrm{~nm}$ source, Galvo speed $-30 \mathrm{~mm} \mathrm{~s}^{-1}$, Power - $1.08 \mathrm{~W}$, No. of scans - 8. (c) Depth distribution plotted for the two cavities. The shaded areas represent the depth distribution and the red and blue curve are the Gaussian fit for the distribution data from which the depth window is calculated

The laser milling recipes are studied at both low and high removal rate. The ablation depth and volume are plotted as a function of milling time in Fig. 10. Both these values are linear with respect to milling time. It is important to distinguish the removal rate measured in terms of ablation depth and volume because the measured depth does not take into account the milling area. For the low removal rate case, the milling geometry is $1.26 \times 1.72 \mathrm{~mm}^{2}$ and for high removal rate, it is $1.66 \times 2.12 \mathrm{~mm}^{2}$. It can be seen in Fig. 10a that for high removal rate case, the volume and depth increase with the same 
slope with increasing time. For the low removal rate case, the depth has a larger slope while volume has a smaller slope. Hence, plotting ablated volume as a function of time gives a better picture of the removal rate. The volume removal rate for the high removal rate case is $6.87 \times 10^{6} \mu \mathrm{m}^{3} \mathrm{~s}^{-1}$ and for low removal rate one is $3.53 \times 10^{5} \mu \mathrm{m}^{3} \mathrm{~s}^{-1}$.

In addition to removal rates, it is essential to understand tradeoffs between the removal rates and the quality of the cavity. The depth window is taken as a measure for the quality of the cavity. We find that lower removal rates do not necessarily give a better quality of the cavity. This is because the depth window also depends on the number of scans over the milling area in addition to chosen processing parameters. It can be seen in Fig. 10c that the ablated volume and the depth window have the same slope on the chosen scale for the high removal rate case. For the low removal rate case, the slope of the depth window is relatively larger compared to the ablated volume. Thus for removing the same volume, it may be better to use faster removal rate but at the cost of larger heat affected zone underneath the cavity.

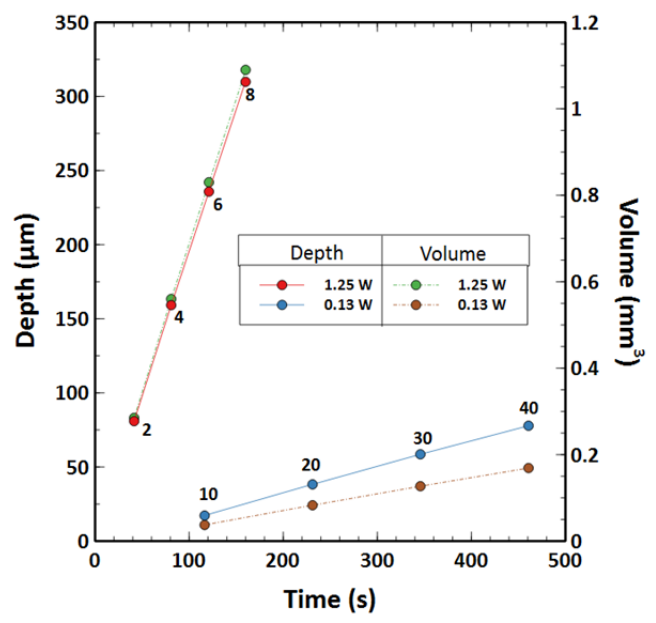

(a)

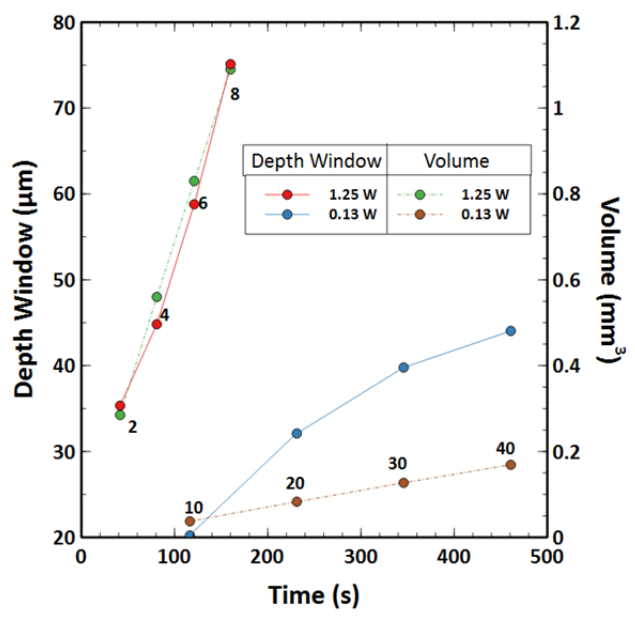

(b)

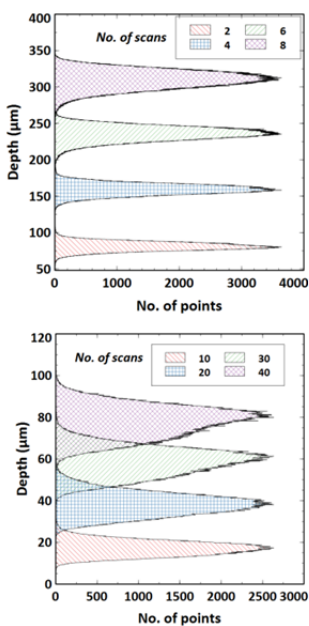

(c)

Figure 10. (a) Cavity depth and ablated volume as a function of milling time. The number of laser scans are indicated next to the markers (b) Depth windows as a function of milling time (c) Depth distributions for the different cavities

\subsection{FLAME process: SP9T switch}

FLAME process has been applied to suspended membranes of RF circuits. The circuit which is studied is the SP9T switch and is described in the next section. Laser milling parameters of the SP9T switch has been described in previous work ${ }^{16}$. It is a two-step milling where larger cavity is milled inside a smaller one. The final average depth of the smaller cavity is $\sim 630 \mu \mathrm{m}$. Volume removal rates that are used for the switch are $8.48 \times 10^{6} \mu \mathrm{m}^{3} \mathrm{~s}^{-1}$ and $7.02 \times 10^{5} \mu \mathrm{m}^{3} \mathrm{~s}^{-1}$ for the fast and slow removal steps respectively. The final depth window that is obtained for the smaller cavity is $121.2 \mu \mathrm{m}$. The deepest point is deeper than the average depth of the cavity approximately by half the depth window which is $\sim 700 \mu \mathrm{m}$. The total thickness of the SOI die is $\sim 750 \mu \mathrm{m}$. When the final cavity is observed, microholes are seen and cannot be fully avoided during laser milling. The depth of these holes cannot be measured by the profilometer. Hence, the final etch depth is set such that the deepest point calculated using the depth window is higher than the thickness of the sample by few microns so that these microholes do not penetrate the sample from the other side.

After the laser milling process, the remaining silicon is etched using $\mathrm{XeF}_{2}$ dry etching method. The sample is exposed in vacuum chamber to $\mathrm{XeF}_{2}$ gas for a fixed cycle time and after that $\mathrm{XeF}_{2}$ is pumped out. This process is repeated over multiple cycles. The parameters used for the etching are cycle time of $10 \mathrm{~s}$ and $\mathrm{XeF}_{2}$ pressure of 3 Torr. The etching rate can vary a lot for this process depending on the temperature and the exposed surface area. The etched cavity is imaged in an optical microscope after every 25 cycles as shown in Fig. 11. The regions which are locally deep as observed in the profilometer are etched first. After subsequent cycles of etching, the etching of silicon is complete under the cavity. Since $\mathrm{XeF}_{2}$ is an isotropic etchant, the sidewall is also etched. This needs to be taken into account while designing the milling geometry for the final desired membrane dimensions. 
(a)

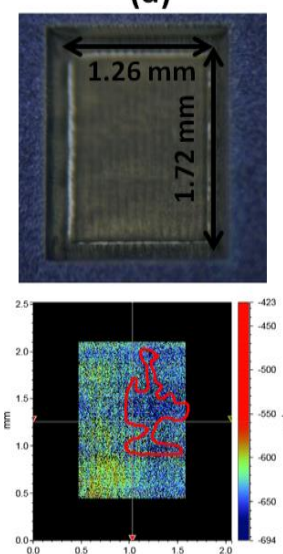

(b) (c)
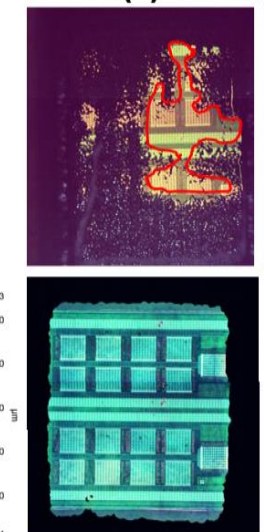

(d) (e)

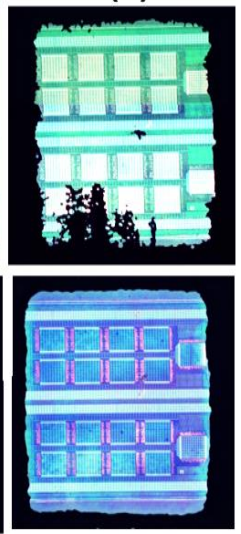

(f)

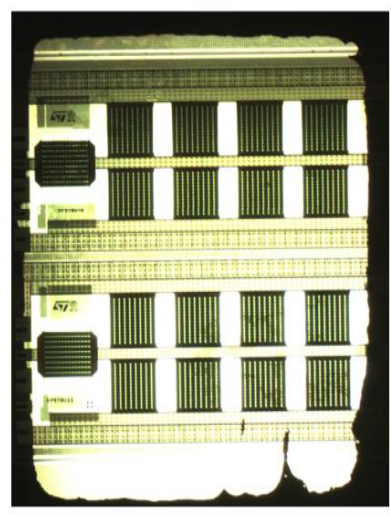

(g)

Figure 11. (a) Cavity made for membrane suspension of SP9T switch (b) Profilometer scan showing the local depth variation .Remaining silicon after $\mathrm{XeF}_{2}$ etch steps (c) After 25 cycles (d) After 50 cycles (e) After 75 cycles (f) After 100 cycles. (g) Circuit partially transparent as seen from the front side with backlight on.

\section{RF CHARARCERIZATION OF MEMBRANES}

\subsection{SP9T switch description}

In order to demonstrate the practical applications of SOI membranes, a study has been done on an SP9T switch designed in STMicroelectronics 130nm SOI CMOS technology. This is an important circuit in Front End Modules (FEM) of RF systems. The switch linearity and small signal parameters study can delineate the impact of substrate in real circuits.

The implemented SP9T structure is shown in Fig. 12. It has a 2-ports configuration containing a single ON branch and 8 OFF branches. The shared gate and body bias control the ON/OFF state of these branches.

The RF characterization is performed on two versions of the switch comprising gate lengths $-\mathrm{Lg}_{\mathrm{g}}$ of 0.18 and $0.22 \mu \mathrm{m}$, respectively. Each switch is characterized at 4 DC bias conditions. Two kinds of specialized RF-SOI wafers are tested: High-resistivity (HR) and Trap-Rich (TR) also referred to as enhanced signal integrity (e-SI), to compare membrane performance with the state-of-the-art RF substrates.

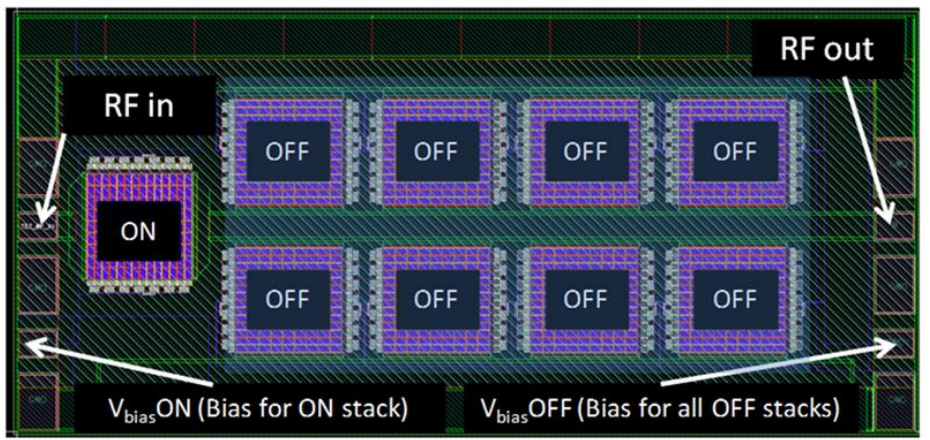

\begin{tabular}{|c|c|c|c|c|}
\hline $\begin{array}{c}\text { Bias } \\
\text { condition }\end{array}$ & B1 & B2 & B3 & B4 \\
\hline $\mathrm{V}_{\text {bias }} \mathrm{ON}(\mathrm{V})$ & 2.5 & 3.3 & 3.3 & 3.6 \\
\hline $\mathrm{V}_{\text {bias }} \mathrm{OFF}(\mathrm{V})$ & -1.75 & -1.75 & -2 & -2 \\
\hline
\end{tabular}

Figure 12. SP9T switch structure which is suspended using FLAME process. The gate and body are tied to same potential internally for each branch. The gate/body bias control exists for one ON branch and it is shared for the 8 OFF branches

\subsection{RF characterization analysis}

The substrate capacitances are non-linear and hence they contribute to harmonics generation. The removal of substrate mitigates these capacitances. Additionally, resistive losses resulting from the penetration of field lines into the substrate are eliminated. As a consequence, both the small-signal and large-signal performance of device is expected to improve. 
The linearity improvement is clearly seen for the HR substrate as plotted in Fig. 13 where $\Delta \mathrm{H} 2=19.1 \mathrm{~dB}$ and $\Delta \mathrm{H} 3=5.5$ $\mathrm{dB}$ for $\mathrm{Lg}=0.18 \mu \mathrm{m}$ at the process technology gate bias specification of $2.5 \mathrm{~V}$. Measurements were performed at $\mathrm{f}_{\mathrm{o}}$ of $1.22 \mathrm{GHz}$. As seen here, the circuit behavior is similar at bias B2, B3 and B4 and hence following discussions compare only B1 and B2.

The TR substrate is an improved version of the HR substrate which is the best available for RF-SOI applications. As given in Fig. 14, a $\Delta \mathrm{H} 2=8.8 \mathrm{dBm}$ at $\mathrm{B} 1$ for both channel lengths is obtained while $\mathrm{H} 3$ remains about the same.
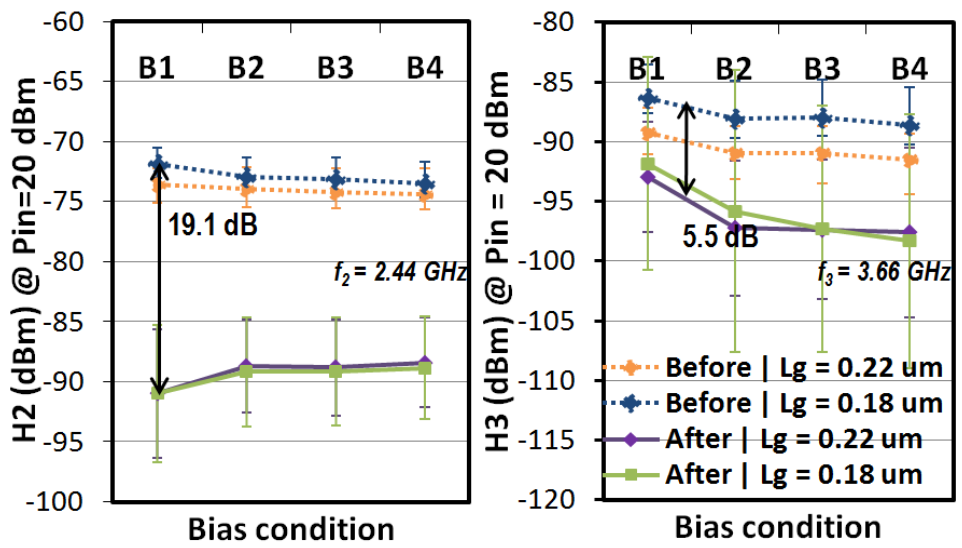

Figure 13. 2nd and 3rd Harmonics (H2/H3) comparison after substrate removal for High Resistivity substrate. The four bias conditions B1-B4 are bias conditions specified in Fig. 12. The substrate impact is strongly seen for H2 compared to H3.

After linearity, small signal measurements have been performed to quantify the insertion losses and matching behavior of the circuits. As seen in Fig. 15, both $S_{21}$ and $S_{11}$ are improved for all bias conditions and channel lengths for HR substrate. The reduction in insertion loss is $\sim 0.4 \mathrm{~dB}$ and $\mathrm{S}_{11}$ is reduced by $4 \mathrm{~dB}$ thanks to the reduction in reactive component of input impedance of switch.
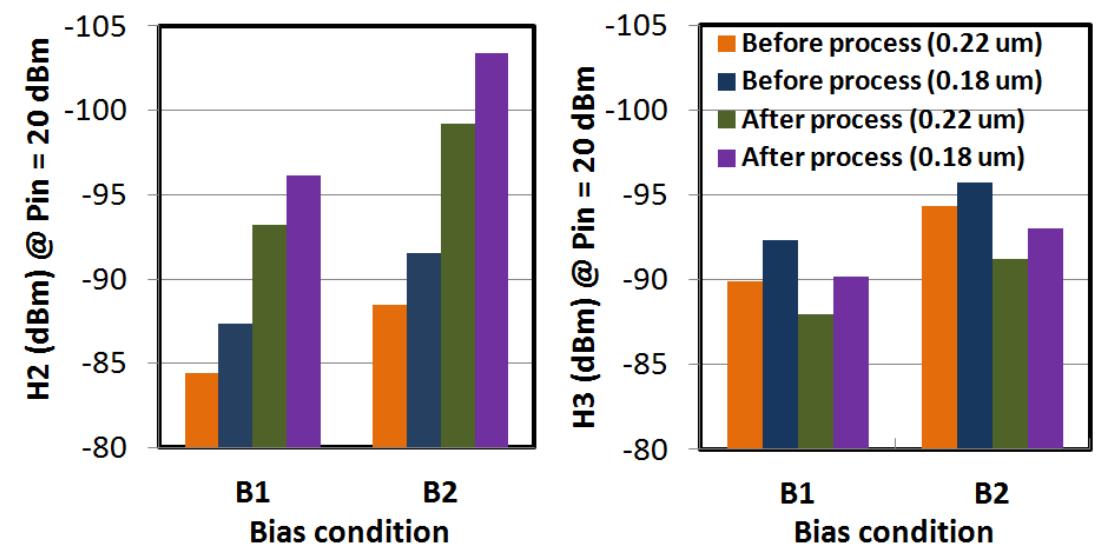

Figure 14. 2nd and 3rd Harmonics (H2/H3) comparison after substrate removal for Trap-Rich substrate. The substrate impact is seen only for $\mathrm{H} 2$ while $\mathrm{H} 3$ in not impacted appreciably. 


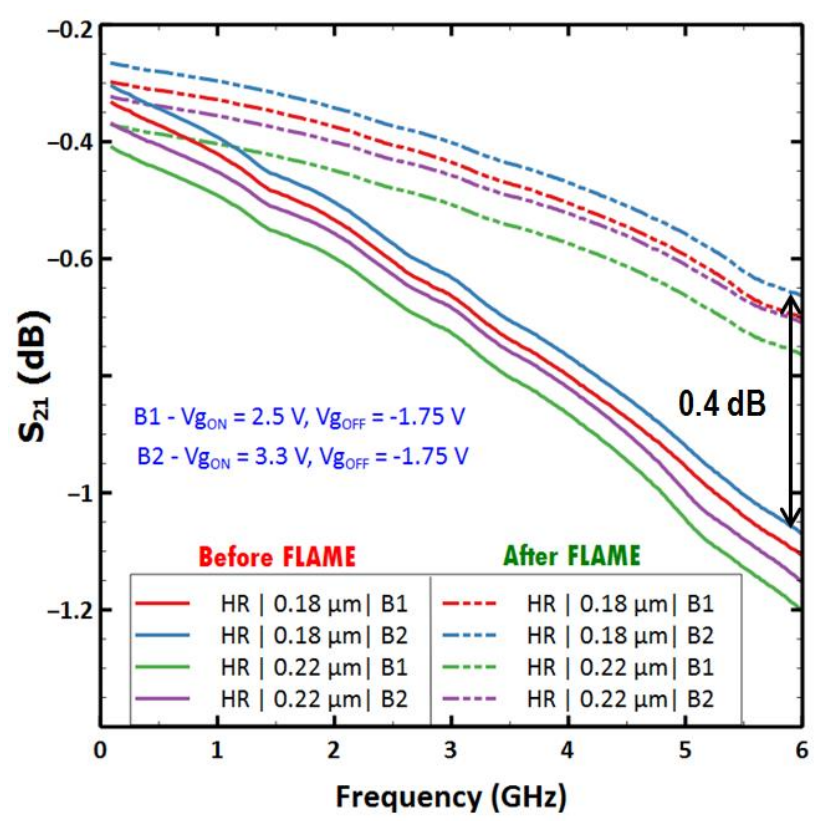

(a)

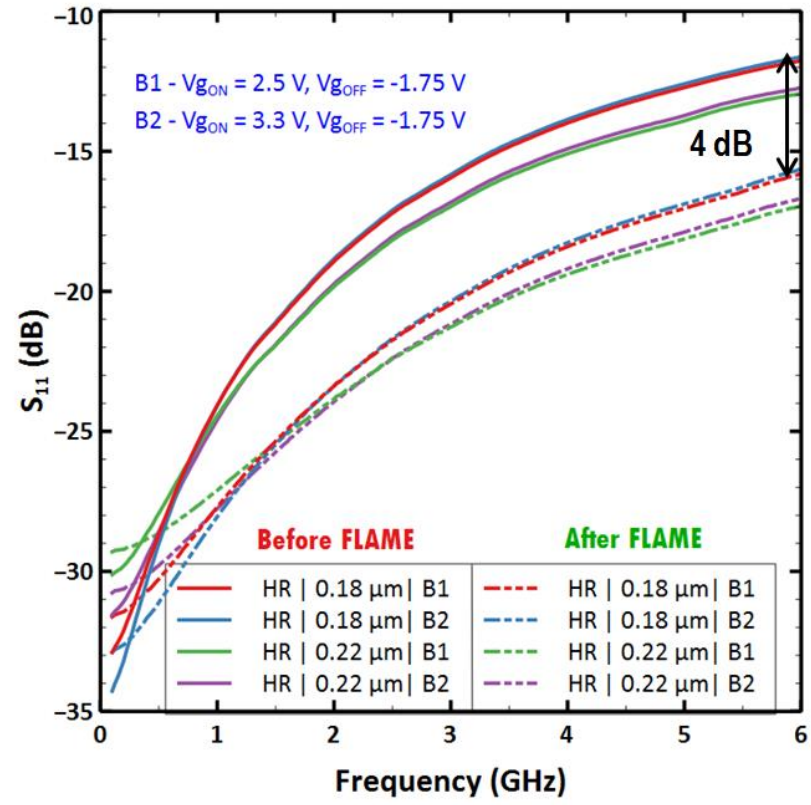

(b)

Figure 15. Small signal S-parameters measurement on High-Resistivity substrate showing (a) $S_{21}$ (b) $S_{11}$

In Fig. 16, S-parameters are plotted for TR substrate. Here, the improvement in $\mathrm{S}_{11}$ remains about the same as HR. The reduction is $\mathrm{S}_{21}$ is $\sim 0.3 \mathrm{~dB}$, which is less as compared to HR because effective substrate conductivity is smaller in TR. While there are differences between TR and HR before FLAME process, the small signal behavior is the same after the process.

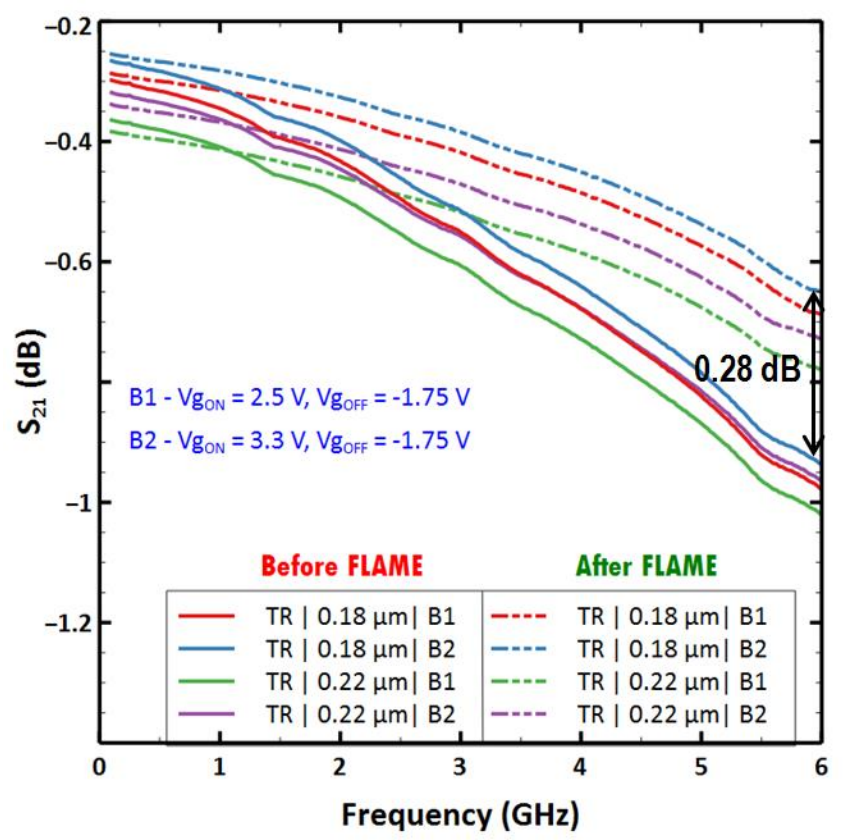

(a)

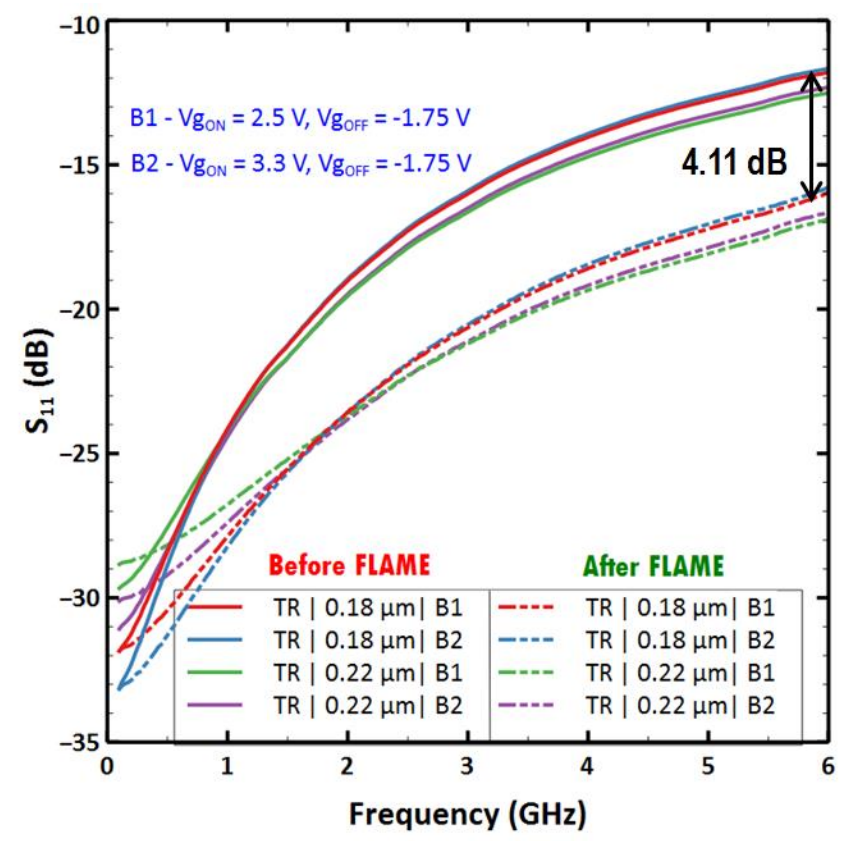

(b)

Figure 16. Small signal S-parameters measurement on Trap-Rich substrate showing (a) $S_{21}$ (b) $S_{11}$ 
Finally, Fig. 17 shows the linearity behavior for HR substrate for varying area of silicon left under the circuit. It shows that the presence of silicon in a small part of the circuit does not give improvement in linearity and hence it is important to accurately define the removal areas on silicon. This will be critical not only for the performance but also for reliable de-embedding procedures when making studies on such membranes.
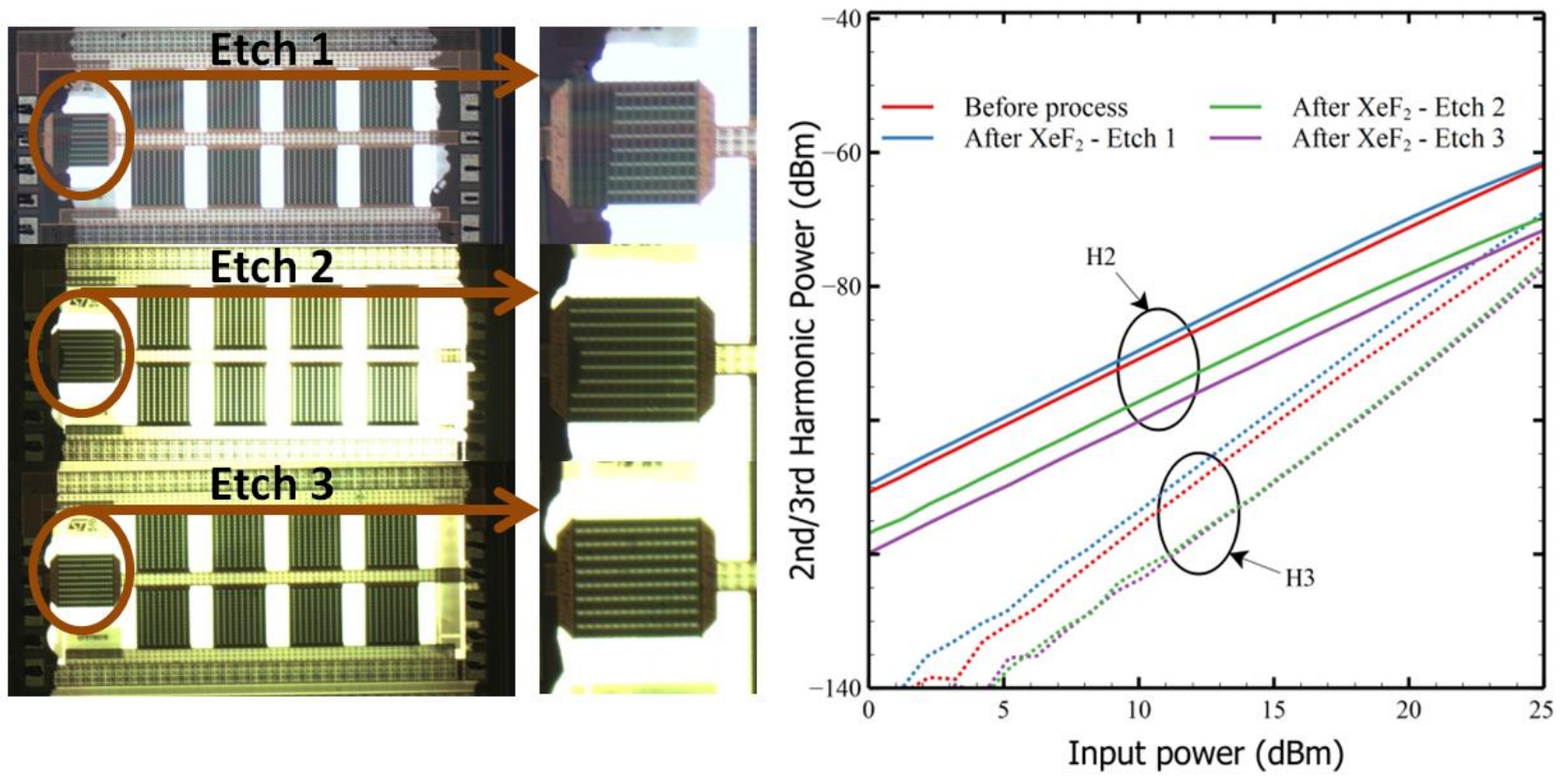

Figure 17. Sensitivity of circuit linearity to area of silicon removed under the circuit. Even presence of small area of silicon under the active zone can significantly affect the H2, H3 behavior of the circuit.

The power handling capability of the switch is an important factor to consider when silicon which is a good thermal conductor is removed under the circuit. We have found that despite there being no silicon for heat dissipation, the switch can handle up to $+30 \mathrm{dBm}$. In order to improve the power handling, efficient thermal management would be necessary.

\section{CONCLUSION}

Femtosecond laser micromachining has been applied for making macro-sized cavities in crystalline silicon using two different source wavelengths. Process parameters have been studied in detail for scribing of trenches to quantify the removal rate and the resulting thermal effects. After knowing the ablation rates and relative thermal impact of chosen process parameters, laser milling is studied. The effect of redeposition of laser plume needs to be considered during laser milling as redeposited matter can interact with the laser beam during the milling process. Depth window has been defined as a measure of laser milling quality because different process parameters result in different local variation of depths. These studies have been applied for the two step milling of cavity under SP9T switch circuit. $\mathrm{XeF}_{2}$ etching is used after laser milling to suspend the SP9T circuit. RF characterization has been performed for the suspended SP9T switch circuit. The results show that there is an improvement in small-signal and large-signal performance metrics. The obtained performance is better than the state-of-the-art Trap-Rich SOI substrate which is the best available SOI substrate for RF-SOI applications. The FLAME process is equally suitable for fabricating pressure sensors in SOI substrate. This opens up potential for laser ablation in high performance RF-SOI and also SOI-MEMS. 


\section{ACKNOWLEDGEMENT}

This work was supported by: (i) Philippe Cathelin and Jérome Lajoinie for SP9T switch design and samples (ii) The STMicroelectronics-IEMN common laboratory (iii) The French government through the National Research Agency (ANR) under program PIA EQUIPEX LEAF ANR-11-EQPX-0025 and (iv) The French RENATECH network on micro and nanotechnologies.

\section{REFERENCES}

[1] Russbueldt, P., Mans, T., Weitenberg, J., Hoffmann, H. D. and Poprawe, R., "Compact diode-pumped 1.1 kW Yb:YAG Innoslab femtosecond amplifier,” Opt. Lett., OL 35(24), 4169-4171 (2010).

[2] Mincuzzi, G., Rebiere, A., Faucon, M., Kling, R. and Lopez, J., "New fast galvo scanner head for high throughput micromachining," Laser-based Micro- and Nanoprocessing XII, U. Klotzbach, K. Washio, and R. Kling, Eds., 34, SPIE, San Francisco, United States (2018).

[3] Weber, R., Graf, T., Berger, P., Onuseit, V., Wiedenmann, M., Freitag, C. and Feuer, A., "Heat accumulation during pulsed laser materials processing," Optics Express 22(9), 11312 (2014).

[4] Venkatakrishnan, K., Sudani, N. and Tan, B., "A high-repetition-rate femtosecond laser for thin silicon wafer dicing," Journal of Micromechanics and Microengineering 18(7), 075032 (2008).

[5] Halbwax, M., Sarnet, T., Delaporte, P., Sentis, M., Etienne, H., Torregrosa, F., Vervisch, V., Perichaud, I. and Martinuzzi, S., "Micro and nano-structuration of silicon by femtosecond laser: Application to silicon photovoltaic cells fabrication," Thin Solid Films 516(20), 6791-6795 (2008).

[6] Nejadmalayeri, A. H., Herman, P. R., Burghoff, J., Will, M., Nolte, S. and Tünnermann, A., "Inscription of optical waveguides in crystalline silicon by mid-infrared femtosecond laser pulses," Optics Letters 30(9), 964 (2005).

[7] Li, J. and Ananthasuresh, G. K., "A quality study on the excimer laser micromachining of electro-thermalcompliant micro devices," Journal of Micromechanics and Microengineering 11(1), 38-47 (2001).

[8] Panzner, M., Kasper, J., Wust, H., Klotzbach, U. and Beyer, E., "Processing of silicon by Nd: YAG lasers with harmonics generation," Photon Processing in Microelectronics and Photonics 4637, 496-505, International Society for Optics and Photonics (2002).

[9] Lee, S., Yang, D. and Nikumb, S., "Femtosecond laser micromilling of Si wafers," Applied Surface Science 254(10), 2996-3005 (2008).

[10] Lei, C., Pan, Z., Jianxiong, C. and Tu, P., "Influence of processing parameters on the structure size of microchannel processed by femtosecond laser," Optics \& Laser Technology 106, 47-51 (2018).

[11] Fiorenza, J. G. and Alamo, J. A. del., "Experimental comparison of RF power LDMOSFETs on thin-film SOI and bulk silicon," IEEE Transactions on Electron Devices 49(4), 687-692 (2002).

[12] Issakov, V., Rimmelspacher, J., Werthof, A., Hagelauer, A. and Weigel, R., "Experimental study on substrate coupling in bulk silicon and RF-SOI CMOS up to $110 \mathrm{GHz}$," 2017 IEEE MTT-S International Microwave Symposium (IMS), 111-113, IEEE, Honololu, HI, USA (2017).

[13] Li, P., Shen, Q., Chang, H. and Li, E., "High-accuracy silicon-on-insulator accelerometer with an increased yield rate," Micro \& Nano Letters 10(10), 477-482 (2015).

[14] Ikoma, Y., Yahaya, H., Kuriyama, K., Sakita, H., Nishino, Y. and Motooka, T., "Semiconductor nanopores formed by chemical vapor deposition of heteroepitaxial SiC films on SOI(100) substrates," Journal of Vacuum Science \& Technology B, Nanotechnology and Microelectronics: Materials, Processing, Measurement, and Phenomena 29(6), 062001 (2011).

[15] Raskin, J.-P., Iker, F., André, N., Olbrechts, B., Pardoen, T. and Flandre, D., "Bulk and surface micromachined MEMS in thin film SOI technology," Electrochimica Acta 52(8), 2850-2861 (2007).

[16] Bhaskar, A., Philippe, J., Berthomé, M., Okada, E., Robillard, J.-F., Gloria, D., Gaquière, C. and Dubois, E., "Large-area femtosecond laser ablation of Silicon to create membrane with high performance CMOS-SOI RF functions," presented at IEEE ESTC 2018, 6.

[17] Crawford, T. H. R., Borowiec, A. and Haugen, H. K., "Femtosecond laser micromachining of grooves in silicon with 800 nm pulses," Applied Physics A 80(8), 1717-1724 (2005). 